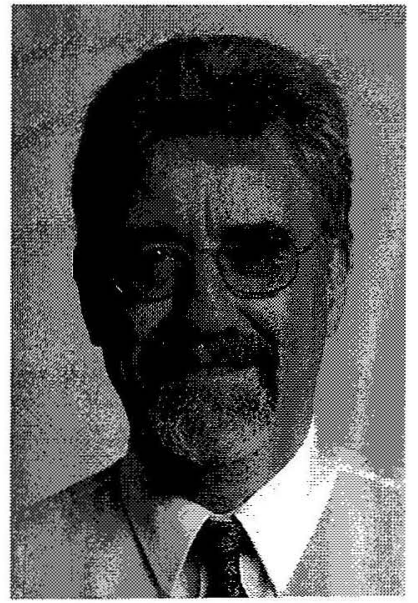

\title{
HEALTH AND SAFETY OF AIRCREW: A CRITIQUE OF THE NATIONAL AND INTERNATIONAL DEBATES
}

\author{
Colin Boyd and Felicity Lamm \\ Department of Management \& \\ Employment Relations \\ The University of Auckland
}

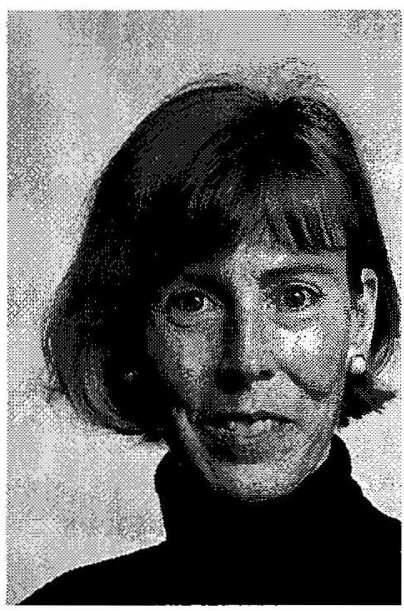

\begin{abstract}
There are a number of current debates about the enforcement of occupational health and safety of aircrew and about their levels of injury and illness. The impetus for these debates are the regulatory reforms of occupational health and safety taking place in both New Zealand and overseas. This paper aims to provide an informed response to this discourse on the health and safety of aircrew by drawing on a number of sources. The paper presents a critique of the legislation governing the health and safety of aircrew and of the industry's response to possible legislative reforms. The paper also analyses civil aviation safety practices both nationally and internationally, and will argue that civil aviation authorities are not necessarily the best agencies to enforce and promote occupational health and safety in the airline industry.
\end{abstract}

